\title{
DRONE-BASED BRIDGE INSPECTION IN HARSH OPERATING ENVIRONMENT: RISKS AND SAFEGUARDS
}

\author{
MOSTAFA ALIYARI ${ }^{1}$, BEHROOZ ASHRAFI $^{2}$ \& YONAS ZEWDU AYELE ${ }^{1}$ \\ ${ }^{1}$ Faculty of Engineering, Østfold University College, Fredrikstad, Norway \\ ${ }^{2}$ Department of Engineering and Safety, UiT The Arctic University of Norway, Troms $\varnothing$, Norway
}

\begin{abstract}
The inability to effectively and systematically identify and measure the damage in bridges will lead to an acceleration and dangerous deterioration of the health state of these structures. To repair and replace the aging and damaged bridge infrastructures, and prevent catastrophic bridge collapse, there is an urgent need to develop reliable, innovative, and efficient approaches to the performance assessment and inspection of bridges. Unmanned aerial vehicles, also knowns as drone, technology has found its way into a number of civilian applications including inspection in the last 20 years, predominantly due to lower cost and tangible scientific improvements. The intent of this paper is to map the current state-ofthe-art drone-enabled bridge inspection practices and investigated their associated hazards and risks. This paper will integrate scenario prediction and, assess hazards as well as the social and environmental loss in the case of drone-enabled bridge inspection. Further, this paper will follow rather closely a threephase process: hazard identification, hazard analysis, and hazard evaluation, all executed with qualitative data and methods by experts of a variety of fields, methodologies for recognition of the impact of cold operating environment on the performance of drone and drone-pilots, creative interpretation of the hazard factors of identifiable problems. The proposed preliminary hazard analysis (PHA) is exemplified via drone-enabled inspection of Håkenby bridge, which is located in the Viken county, in the eastern part of Norway.
\end{abstract}

Keywords: cold environment, drone inspection, drone, drone-enabled bridge inspection, preliminary hazard analysis (PHA), risk assessment.

\section{INTRODUCTION}

Bridges are key elements of the road infrastructures; and, they have proven to be very susceptible to deterioration and collapse because of ineffective and, in some cases, inappropriate inspection techniques. According to various aftermath reports, see e.g. [1] and [2-4], deterioration related issues, such as fatigue fracture, aging of materials, caused most of the bridge failure. One of the most recent examples of bridge failure, is the catastrophic collapse of Morandi Bridge, in the northwest Italian city of Genoa, in august 2018, with the death toll to 43. According to experts, the Morandi Bridge, had been suffering from deterioration (degradation) and was under maintenance in the time of collapse. Indeed, the collapse of a bridge has an immediate impact on the people directly and the surrounding communities for years. It also has an important social, environmental $\left(\mathrm{CO}_{2}\right)$ and economic consequence such as re-routing, congestion, demolishing, building, legal, etc. The collapse or a closure of a bridge due to critical damage prevent the transport of goods and people for long periods of time. The typical design and construction of a bridge takes 2-5 years. Therefore, the loss and recovery are at a high cost to the economy. For instance, back in 2015, the collapse of a Skjeggestad Bridge in Norway prevented the use of the bridge for more than a year, precluding the passage of 20,500 vehicles per day and subsequently costing around USD17 million to rebuilt it [1].

Henceforth, to ensure public safety, identify, and detect structural damage early, when it can be repaired at the lowest possible cost, public roads administrations and transportation agencies on a regular basis inspect bridges. Although enormous efforts [2-4] have been done 
to secure efficient road transport system, still there exist challenges in bridge inspection and maintenance. Some of the challenges with the conventional bridge inspections are:

- Costly and time-consuming inspection practices with high safety risks: (1) the average cost of inspection per bridge varies from USD4,500 to USD10,000 [5]; and, the current inspection techniques requires closing traffic lanes for the span of the inspection, which can normally take between 1 and 3 days causing traffic congestions; (2) Inspectors are exposed to significant safety risks when operating in areas of limited accessibility and any equipment needed may pose a serious disruption to traffic flow [6].

- Lack of hazard identification and risk assessment: to minimize the impact of bridge failure, accurate risk measure of the infrastructure is very essential [7, 8]. The current bridge damage detection, inspection and monitoring tools are not capable to capture the real-time system risk profile.

- Inefficient damage identification and quantification tools: by using traditional inspection tools, it is demanding to identify cracks and other anomalies, especially elements without ease of access. This led to an acceleration and dangerous deterioration of the health state of these structures.

- Laborious and inefficient bridge management systems with no visualisation tools: current bridge management systems are laborious and inefficient, consuming both time and resources. Many systems provide little to no visualisation tools nor decision support, which may significantly depreciate the spatial and temporal context and offer limited interpretability to engineers with no previous knowledge of the specific structure.

That means that by employing the traditional inspection tools, it is demanding to detect most of risk factors solely based on human vision. In other terms, the current bridge damage detection procedures, produces inspection and monitoring tools, which are non-resilient and, are not capable to capture the timely 'near' real-time system performance. Moreover, the inability to effectively and systematically identify and measure the damage in bridges will lead to an acceleration and dangerous deterioration of the health state of these structures.

Henceforth, to repair and replace the aging and crumbling bridge infrastructures, and prevent catastrophic bridge collapse, there is an urgent need to develop reliable, innovative, and efficient approaches to the performance assessment and inspection of bridges. One of the latest advancements in bridge inspection is employing unmanned aerial vehicles, also knowns as drones for performing inspection for hard-to-reach locations and parts of any complex bridge. That means that one of the key benefits of using drones for inspection is the reduction of risks associated with current bridge inspection methods, which include - but are not limited to - rope systems and special inspection vehicles [6]. The other principal advantage is reduction of costs of bridge inspections. Moreover, bridge inspection using drones can be carried out during the daytime without closing a bridge. Drone-mounted sensors can be used to collect large amounts of inspection data, which paves the way for increased digitization of bridge inspection and monitoring processes. An automated, digitized bridge inspection combined with drone images can detect bridge damage at a level likely to be impossible for a human inspector. It can also reduce much of the uncertainty and weaknesses associated with an inspector's personal assessment of the severity of structural damage.

However, previous problems related to drones included low quality image and video capabilities, notably sensitive under poor lighting conditions and high wind speeds; see e.g. Jung et al. [9] and Foreman et al. [10]. Further, employing drones for bridge inspection is still considered to be at an early stage from a practical point of view and a more systematic 
and reliable approach is needed $[3,8,11,12]$. Further, humans are 'designed' to operate in very narrow temperature range and thus wind, icing and darkness reduce the operational effectiveness considerably increasing the possibility of making mistakes or being inaccurate during drone-flights. In other words, the cold operational environments, which are common in northern Europe, such as Norway, have significant effect on the performance of the drones and drone pilots, and these magnify the hazards associated with the bridge inspection practices. Thus, both technical and environmental-related factors that affect the performance of drones and drone pilots must be recognized and quantified throughout the various phases of the bridge inspection process.

Henceforth, to fill this gap, in this paper, we integrated scenario prediction and assess hazards as well as the social and environmental impacts for drone-enabled bridge inspection in cold operating environment. Further, this paper will follow rather closely a three-phase process: hazard identification, hazard analysis, and hazard evaluation, all executed with qualitative data and methods by experts of a variety of fields, methodologies for recognition of weak signals, suitable interpretation of the hazard's factors, or even brainstorming about 'imaging the unimaginable'. The three-phase process can help to have an effective drone-enabled bridge inspection with high level of safety in the cold operating environment.

\section{PROPOSED METHODOLOGY FOR PHA VIA EXPERT JUDGEMENT}

In this study we proposed a methodology for PHA for drone-enabled bridge inspection based on expert judgement (Fig. 1). A PHA is an analysis method that is used as a part of a preliminary strategy, for identifying potential hazards associated with a specific drone system and its applications [14]. As such a core requirement is the identification of the hazards, which the drone might encounter during its life cycle. In order to formulate a combined hazard set,

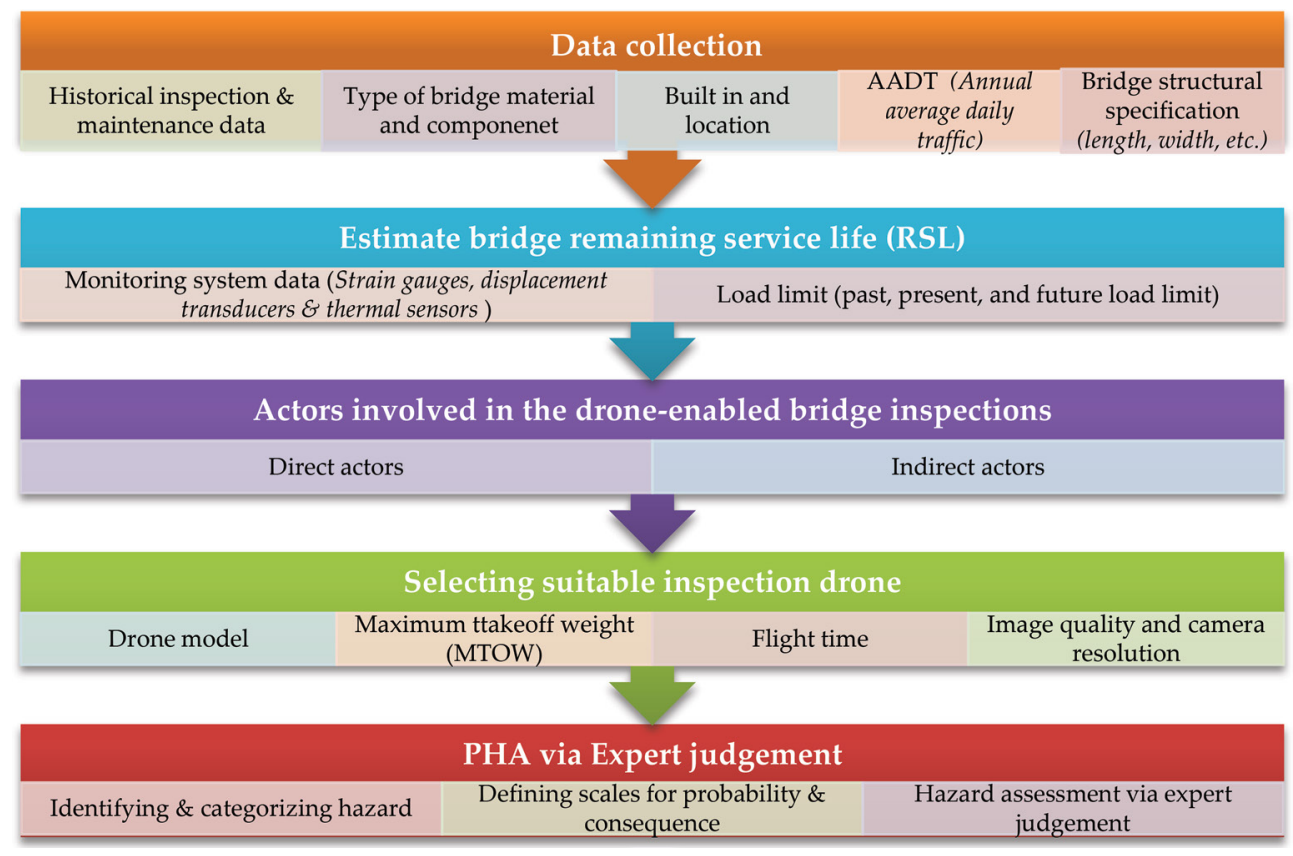

Figure 1: Proposed methodology for PHA via expert judgement. 
which is to be used in assessing risk, the technical hazards analysis and the analysis of the impact of the peculiar environment-related factors on the drone systems and drone pilots are needed to be determined. The term 'hazard' in the context of this paper is 'any real or potential condition that can cause: injury, illness, or death to people; damage to or loss of a system, equipment, or property; or damage to the environment' [15].

To evaluate the peculiar operational risks associated with bridge inspection process, in particular hazards associated with drone-based inspection it is important to map the risks related to the planned activities and the susceptible areas. Bridge inspection is a demanding process and, involves safety hazards and risks for the civil engineers/inspectors, equipment operators, divers, construction workers, and others while they are involved in road or bridge inspection and repair. The US Occupational Safety \& Health Administration [16] have compiled the common hazards associated with the conventional roadway and bridge inspection and repair: (i) falls from the heights or through openings, (ii) structural instability, (iii) contact with downed lines and live electrical equipment and other utilities (such as gas, water), (iv) work on, over, or near water, and (iv) improper ladder or scaffolding use, etc.

\subsection{Stage 1: data collection}

Nowadays, comprehensive data collection and digital documentation are becoming key to transport sector productivity and competitiveness. With current technologies, collecting both internal and external data of any infrastructure are becoming less demanding. However, without effective data collection, this ever-bigger amount of data can become overwhelming. Further, inadequate or poorly designed data collecting and sharing platforms leads to major financial and social challenges, which governments and businesses need to address [17, 18]. Hence, in this step, one has to identify, assess, and utilize the bridge data, which is critically essential for its core activities. Some of these essential data are: (i) historical maintenance and repair data: collecting these data helps identifying a component or part of the bridge, which might have a higher risk of failure. In addition, the historical data can supplement the drone-based inspection process in such a way that the components with known defects can be accurately identified. (ii) Type of bridge component: bridge component are designed to fit the specific case scenario such as highway, railway, pedestrian and so on. Here the data related to the performance or service condition of the key component of the bridge should be collected. Some of the key components of a bridge are: piles, girders, deck beams, abutments, etc. (iii) AADT (annual average daily traffic) and (iv) bridge structural specification such as length, width, etc. and (v) information about the when the bridge is built in and its location.

\subsection{Stage 2: estimate bridge remaining service life (RSL)}

In this stage, the bridge remaining service life (RSL) should be estimated. The RSL is the time remaining for a bridge or its component to perform its functional capabilities before failure [19]. In general, the RSL of existing bridges depends on the past, present as well as forecasted traffic loads. In order to estimate, the bridge RSL it is important to collect the load and vehicle data. This can be done by employing structural monitoring systems, which consists on strain gauges, displacement transducers, and thermal sensors [20]. Further, bridge load tests will help to identify the relationships between a safe load carrying capacity of the bridge and its service condition. 
2.3 Stage 3: identifying the actors involved in the drone-enabled bridge inspections

The focus of this stage is to determine the actors involved in the drone-enabled bridge inspections. These actors are categorised into two different groups - direct and indirect group actors. Direct group actors are actors that have a direct physical contact with the inspection process. Indirect group actors are the actors, which have indirect effects on the Drone-enabled bridge inspection process. Table 1 depicts the direct and indirect group actors.

\subsection{Stage 4: selecting suitable inspection drone}

The key benefit of drone-enabled bridge inspection is the reduction of the above-mentioned risks associated with conventional bridge inspection methods. In this stage, one has to

Table 1: Direct and indirect group actors.

\begin{tabular}{|c|c|c|}
\hline & Actor & Description \\
\hline \multirow{4}{*}{ 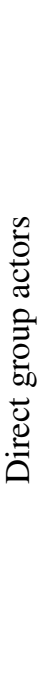 } & The bridge & $\begin{array}{l}\text { The primary unit in the process, which is the focus of the } \\
\text { inspection process. }\end{array}$ \\
\hline & Drone system & $\begin{array}{l}\text { The primary inspection tool for this study and, it } \\
\text { comprises: } \\
\text { - The drone } \\
\text { - drone-pilot: The operator that flies the drone or monitor } \\
\text { it in case of autonomous operations } \\
\text { - IP: inspection personnel that assists the inspection pro- } \\
\text { cess by watching the live feed while the drone is flying } \\
\text { and gathering data }\end{array}$ \\
\hline & $\begin{array}{l}\text { Manual inspection } \\
\text { system }\end{array}$ & $\begin{array}{l}\text { Manual inspection personnel and under-bridge-inspection- } \\
\text { truck (UBIT) }\end{array}$ \\
\hline & Environment & $\begin{array}{l}\text { - Weather conditions: any kind of disruptive weather that } \\
\text { can halt the drone operations } \\
\text { - Lighting conditions: any kind of disruptive lighting that } \\
\text { can cause problems for videos or photos that can be taken }\end{array}$ \\
\hline \multirow{6}{*}{ 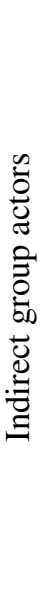 } & Insurance companies & $\begin{array}{l}\text { Insurance companies have an indirect contact with the pro- } \\
\text { cess in terms of insuring the drone itself; and, the drones } \\
\text { possible damages to the surrounding environment }\end{array}$ \\
\hline & Regulatory agencies & $\begin{array}{l}\text { The agencies, such as United States Federal Aviation } \\
\text { Administration (FAA) and, the civil aviation authority of } \\
\text { Norway that will regulate the flying of drone in Norway's } \\
\text { airspace }\end{array}$ \\
\hline & Bridge users & $\begin{array}{l}\text { Anyone that uses the bridge in anyway, such as drivers, } \\
\text { pedestrians, bikers, etc. }\end{array}$ \\
\hline & Ships/boats & Passing boats from under the bridge \\
\hline & Birds and other wildlife & $\begin{array}{l}\text { Any flying birds in the vicinity of the drone-enabled bridge } \\
\text { inspection operations as well as other wildlife animals }\end{array}$ \\
\hline & 3rd party & 3rd party intentional or unintentional involvement \\
\hline
\end{tabular}


investigate the appropriateness of employing drones for specific types of bridges since not every bridge inspection is 'drone appropriate'. Bridge inspection projects, which can be suitable for drone use, include those that [21]: (i) requires expensive and hard-to-set-up equipment to inspect a small section of a bridge. This means that the cost of inspection is significantly high comparing with the very limited use and pay off, (ii) bridges with a an unusually high level of risk and catastrophic consequence, and (iii) bridges that might lead to intense traffic interferences and have a significant impact on traffic.

In this stage, the selection of an appropriate drone for bridge inspection should be carried out. The following considerations needed to be corroborated when selecting the most suitable inspection drone: (i) Drone model: typically, drone-pilot is only as good as the equipment they use. That means that there is no amount of skills, which can overcome poor camera quality or an unstable drone. For bridge inspection, a hexacopter and preferably an octocopter is suitable since they have a high factor of safety should a rotor or three fail. (ii) Maximum Take-off Weight (MTOW): MTOW is the maximum weight authorized for an aircraft while taking-off. While selecting suitable drone, one has to take into consideration the MTOW of the drone. This is to minimize the consequence of an incident, which involves a drone. For instance, the consequence of an incident with a $2.5 \mathrm{~kg}$ drone is exponentially less than with a $25 \mathrm{~kg}$ drone. (iii) Flight time: drone have a wide-range of flying time. It is necessary to select a drone with longer flight times than the ones provided by average commercial drones, from 10 to $30 \mathrm{~min}$, in order to limit the interruptions during inspection due to the need for additional batteries, and (iv) Image quality and camera resolution: in bridge inspection, high quality images as well as high quality videos. Hence, the selected drone has to have a camera with aerial zoom function, for capturing high detail images in hard-toreach locations and parts of any complex bridge. Further, it can also be beneficial to integrate omnidirectional camera on the top of drone for inspecting the underneath of the bridge. For bridge inspection, the video should be high-resolution as well in order to visually observe bridge damage details.

\subsection{Stage 5: PHA via expert judgement}

The PHA has three main sub-steps. Firstly, identification and categorization of the potential hazard should be carried out. Secondly, the scales for probability and consequence should be defined. Finally, the assessment of the identified hazards and the risk profile should be mapped. The PHA is exemplified via drone-enabled inspection of Håkenby bridge, which is located in the Viken county, in the eastern part of Norway.

\section{AN ILLUSTRATIVE CASE STUDY}

The following case study describes the investigative methods and results for preliminary hazard analysis, when employing drones for bridges inspections, in particular in cold operating environment. The location, structure description, access methods, investigation methods, site specific safety analysis and imagery results are discussed for Håkenby bridge. Håkenby bridge is a single lane vehicular bridge in a rural remote setting with light traffic. There was a clear line of sight without any specific obstacles for drone inspection, and there was a safe place next to bridge for drone take-off and landing. Figure 2 illustrates a top view and structure description of Håkenby Bridge.

We have used DJI Matrice 100 drone with Zenmuse Z3 aerial zoom camera with 7’ zoom capacity, for carrying out the drone-enabled bridge inspection. We have tested and trailed autonomous control, by using Z3 cameras and sensors, which can help the drone to autonomously 


\begin{tabular}{|l|l|}
\hline \multicolumn{2}{|l|}{ Key bridge data } \\
\hline Id & $01-0219$ \\
\hline Municipality & Halden \\
\hline County & Viken \\
\hline Built in & 1958 \\
\hline Material & Concrete \\
\hline Length (m) & 16 \\
\hline $\begin{array}{l}\text { AADT } \\
\text { (Annual } \\
\text { average daily } \\
\text { traffic) }\end{array}$ & 350 \\
\hline
\end{tabular}

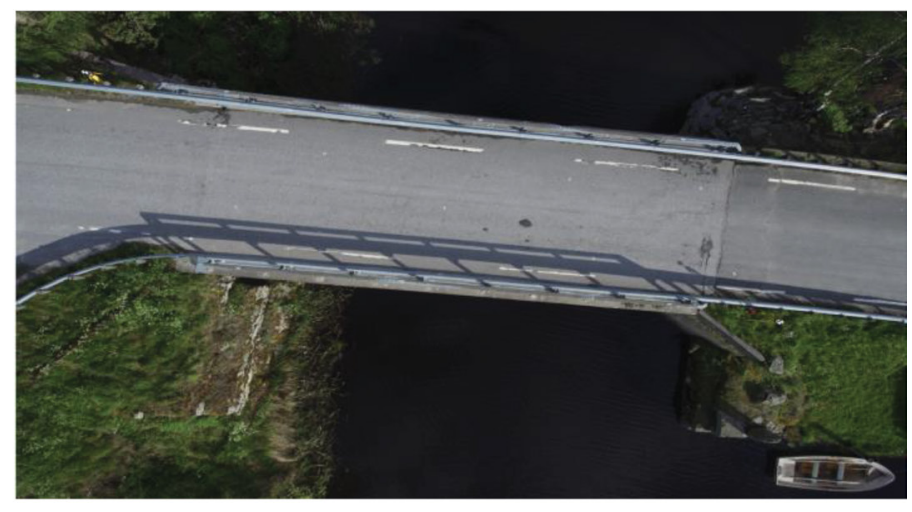

Figure 2: Top view of Håkenby bridge.
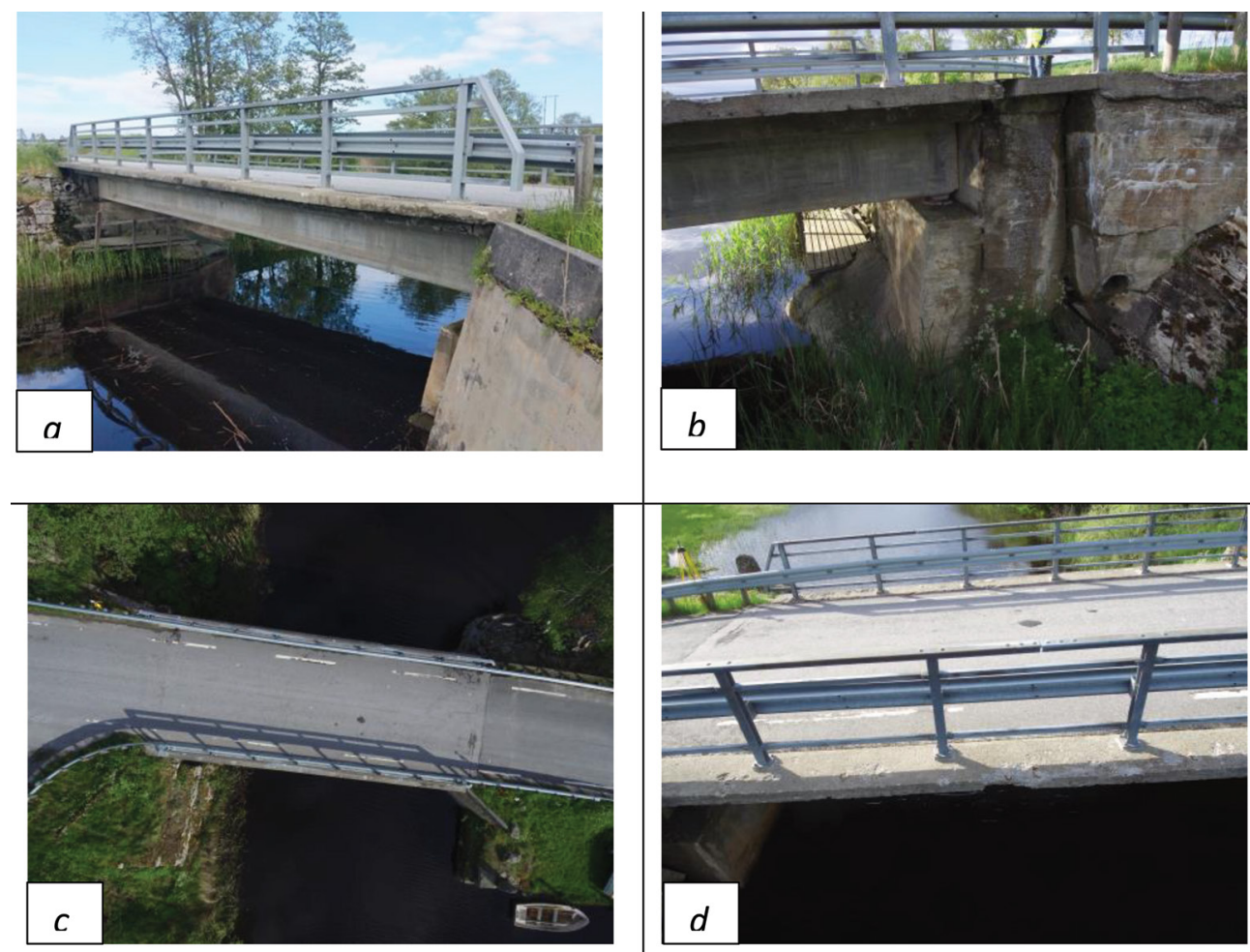

Figure 3: (a) Håkenby bridge side view; (b) Håkenby bridge concrete crack and deterioration; (c) Håkenby bridge top view; (d) Håkenby bridge deck slab damage

avoid obstacles or simply hold altitude in a GPS-denied environment. Other equipment's used are DJI Phantom 4 Pro V2.0, DJI remote controllers, landing platform, GPS antenna \& handheld, total stations, tripods, spare batteries, blades, I-pad \& connection wires to drone remotes, safety helmets, safety boots \& reflective jackets, and tapes \& markers. Figure 3 illustrates the level of details obtained from the drone-enabled imaging for Håkenby bridge. 


\subsection{PHA via expert judgement}

\subsubsection{Hazard identification}

When identifying and categorizing hazards, a reasonable effort has been made to identify those that will have the most significant implications on the strategic decision. Further, it is important to note that a 'hazard' only represents a potential to cause harm. Whether it actually does causes harm will depend on circumstances, such as the type of the hazard, flight duration, etc. In hazard identification, the severity of the harm due to each identified hazard needs to be rated. For example, a significant hazard can be one with the potential to cause a catastrophic, which is very high or severe damage. Identifying hazards in the droneenabled bridge inspection involves finding things and situations that could potentially cause harm to people involved, the drone system, etc. Hazards, during the drone-enabled inspection generally arise from the following aspects of work and their interaction: (i) physical work environment; (ii) equipment and materials used; (iii) inspection tasks and how they are performed; and (iv) bridge inspection design and management of drones. Further, when assessing hazards associated with the drone-enabled inspection in cold regions, including Norway, the effect of the operating environment needs to be analysed thoroughly. This is due to the fact that the cold operating environment is one of the dominant factors, which influences the performance of the inspectors, the function of drones, and then consequently increases the hazards. The lists of the predominant hazards associated with drone-enabled bridge inspection in cold operating environment, is depicted in Table 2.

\subsubsection{Defining the scales for probability and consequence}

For defining the consequence scale criteria, there is a need to define the systems mission. The systems mission can be defined as the ability of a given drone to carry on visual inspection of any bridge within a certain time and within a specified standard. The success and failure of the mission can be defined as follows:

- Mission success: drone completes the mission and gathers the required data within the acceptable standards and return to base intact.

- Mission failure: drone cannot fulfil the minimum data required for inspection process or the drone is destroyed during the mission.

The consequence scale based on the mission success and failure is depicted in Appendix I of the Supplemental Material. On the other hand, for defining the scale for the probability, the conventional probability ranking is adapted and is shown in Supplemental Material, Appendix II.

\subsubsection{Hazard assessment via PHA based on expert judgment}

The basic assumptions in this PHA are: a year-round drone operational window and, the fact that the drone-enabled inspection is carried out in cold operating environment. Since employing drone for bridge inspection is relatively new, there is a lack of historical drone system failure rate data. Hence, judgements provided by those people with expertise in identifying potential hazards and risks of undesirable events are utilised at various stages of this hazard analysis in order to perform effective hazard identification and quantification. Their expertise is used to analyse historical information, define and analyse potential hazards, and evaluate the consequence of undesirable events. 


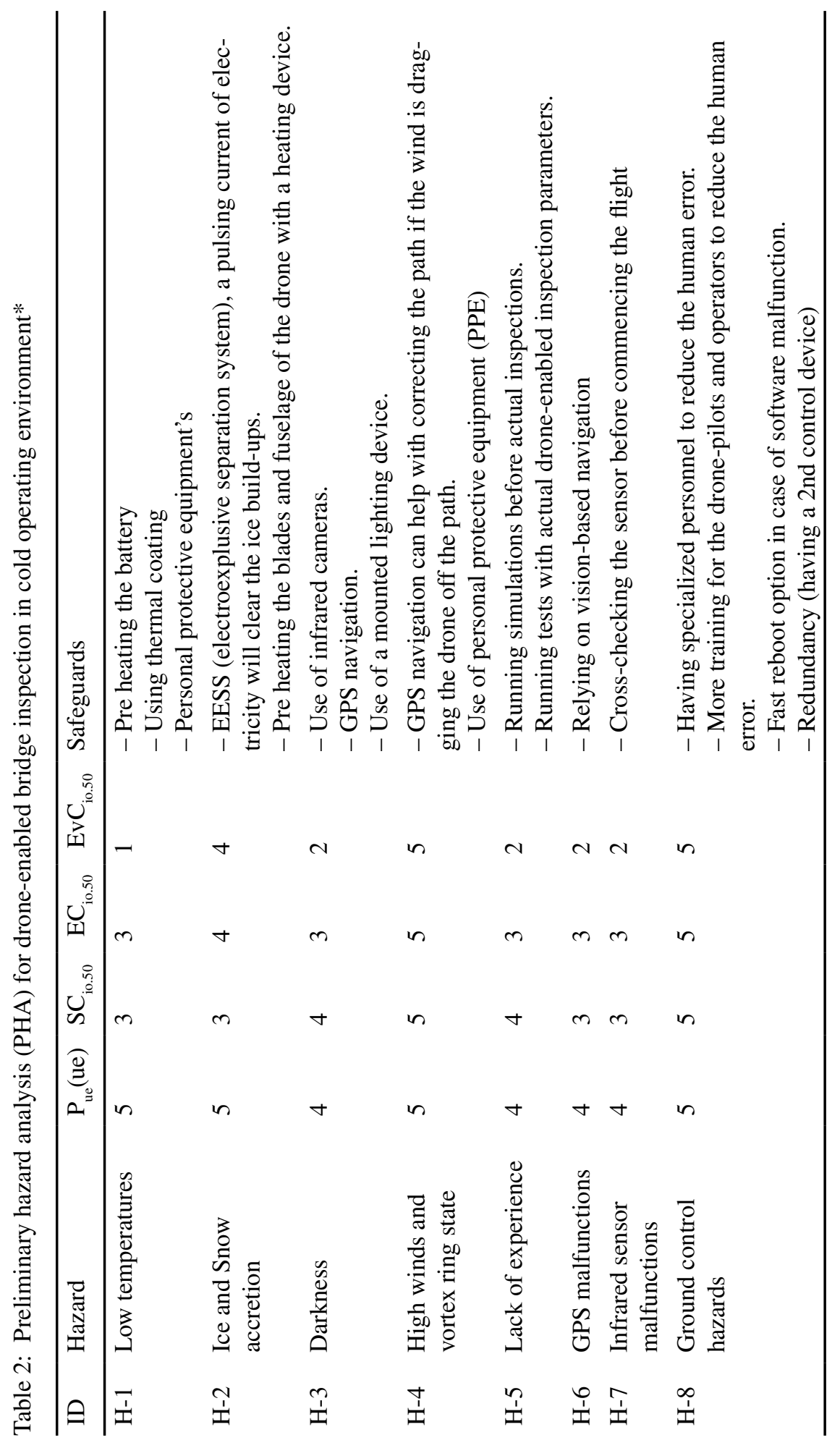




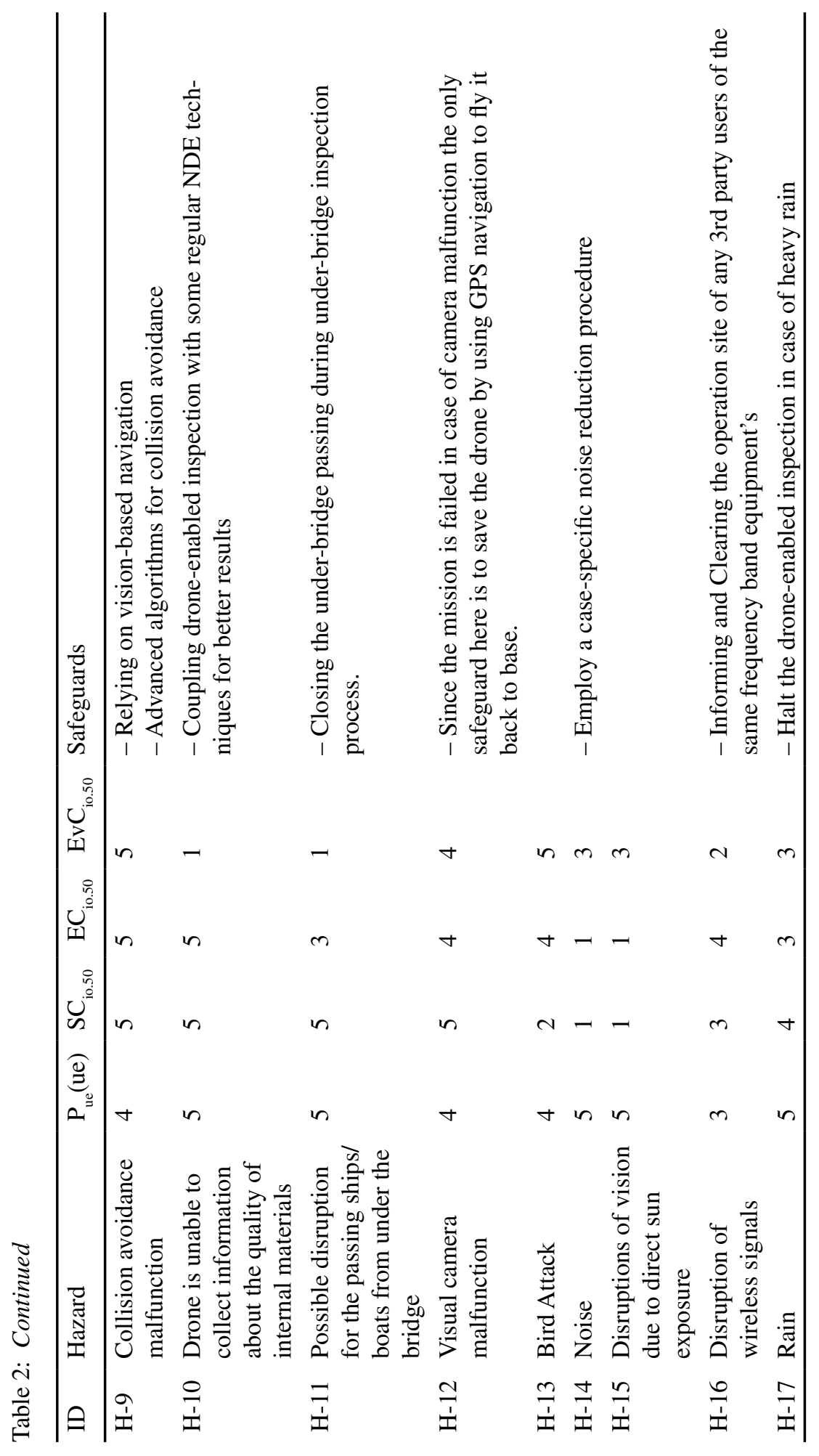


1. Selecting the experts: in this PHA we have employed a criteria suggested by Ortiz et al. [22] regarding how to select experts. As per Ortiz et al. [22] experts collectively would represent a wide variety of background and knowledge. Based on this, here the experts have been chosen by referring their direct involvement in the drone related areas, their experience in bridge inspection procedures, and consulting and leading research projects in the related areas. The chosen experts are categorised into two, namely academics and specialists with hands-on skills on drone flights, know-how in hazards assessment, bridge inspection, meteorology, cold-and climate technology, with 5-15 years of experience in their respective fields.

2. Posing questions to the experts: in order to facilitate the PHA, the surveys are set by reciting the likely hazards and undesirable events. The hazards are proposed for use as guidance, and consequence (safety, economic, and environmental consequences) categories are also postulated. Suppose that we have number of undesirable events. We have then asked the experts to suggest their degree-of-belief probabilities and consequences rating of each undesirable events. Thereafter, we have designated the degree-of-belief probabilities as $\mathrm{P}_{\text {io. } 05}$ as a lower value; $\mathrm{P}_{\text {io.05 }}$ as median value; and $\mathrm{P}_{\text {io. } 95}$ as $95 \%$ percentile value, which is considered as experts' conservative judgement about the undesirable events. Moreover, the experts were also provided the associated consequences as $\mathrm{C}_{\mathrm{i} .05}$, $\mathrm{C}_{\mathrm{io} .05}$, and $\mathrm{C}_{\mathrm{io} .95}$. For illustrating how the process is carried out for determining the categories for probability and consequences, we have included a brief description for the first hazards, $\mathrm{H}-1$, which is low temperature, we have used during the survey.

- Since low temperatures, are common in Norway the value, which is the probability of low temperatures happening, will be in Category 5 with a high probability of occurrence except in mid-summer. Safety consequence $\left(\mathrm{SC}_{\mathrm{io} .50}\right)$ due to the battery discharge will be considered as a minimum because the early warning systems implemented in the drone system will warn the pilot of low battery situations and the pilot can only press the home return button on the remote controller so that the drone will automatically come back to the base. However, degraded human performance, due to low temperature, can lead to some issues on the pilot's performance that will increase the probability of drone collision. Therefore, safety consequences will be considered as Category 3. The economic consequence $\left(\mathrm{EC}_{\mathrm{i} .50}\right)$ due to the battery discharge will be considered significant since if the drone does not have enough battery, then the mission cannot be completed and although the drone will land safely due to battery discharge there are more indirect costs involved in case of a failed operation, due to this fact the economic consequence will be considered as Category 3. The environmental consequences $\left(\mathrm{EvC}_{\text {io.50 }}\right)$ are negligible in this particular hazard are designated as Category 1.

3. The quality of the expert judgements: Hora [23] have pointed out that degree-of-belief probabilities are personal. In addition, these probabilities differ from expert to expert and from time to time. This leads us there is no 'true' probability that one might use as a measure of the accurateness of a single elicited probability. For depicting such kinds of distortion, we employed the weighted distributions approach for each degree-of-belief probability. Thereafter, we have requested the experts to specify 5\% (lower), 50\% (median) and 95\% (upper) values for the potential hazard's probabilities. In addition to calibration, one can employ the concept of convergence, for validating judgement results. In simple terms, as per Chang, et al. [24], convergence, can be realised by soliciting the same fundamental question in several different ways. Henceforth, for fulfilling the above 
two properties and evaluate the quality of experts' judgements, we have calibrated the degree-of-belief probabilities. Subsequently, two scores - calibration and information, have been employed for estimating the non-normalised performance-based weight for each expert . In this PHA, experts are scored on the basis of answers to questions for which the answer is only known to the analyst. The non-normalised performance-based weight for expert $i$, can be defined as follows, based on Cooke [25]:

$$
k_{\mathrm{nnw}_{i}} \propto C\left(E_{i}\right) \times I\left(E_{i}\right)
$$

where:

- $k_{\mathrm{nnw}_{i}}$ is the non-normalised performance-based weight for expert $i$;

○ $C\left(E_{i}\right)$, represents the calibration score for expert $i$;

- $I\left(E_{i}\right)$, represents the information score for expert $i$.

4. Aggregating the expert judgements: we have employed an expert aggregation method is used, for combining the elicited probabilities:

$$
P_{\text {ue }}(\text { ue })=\sum_{\mathrm{i}=1}^{n} k_{\mathrm{nw}_{i}} P_{\mathrm{ue}_{i}}\left(\mathrm{ue}_{i}\right)
$$

where:

$-P_{\text {ue }}($ ue $)$ is the aggregated expert judgement probability of unwanted event.

- $\mathrm{k}_{\mathrm{nw}_{i}}$ is the normalised performance-based weight for expert $\mathrm{i} \mathrm{i}$ and is expressed as:

$$
k_{\mathrm{nw}_{i}}=\frac{k_{\mathrm{nnw}_{i}}}{\sum_{i=1}^{n} k_{\mathrm{nnw}_{i}}} .
$$

Thereafter, the aggregated values of each expert for the hazards, considering the normalised experts' performance-based weight, are calculated and shown in Table 2 and Fig. 4. Note that in Table $2, \mathrm{P}_{\text {ue }}(\mathrm{ue})$ is the probability, $\mathrm{SC}_{\text {i. } 50}$ is defined as median safety consequence, $\mathrm{EC}_{\mathrm{io.50}}$ is defined as a median economic consequence, and $\mathrm{EvC}_{\mathrm{i} .50}$ is defined as a median environmental consequence.

From the PHA results, we can deduce that: (i) the safety consequence of the hazards for $\mathrm{H}-4$, which is wind hazard and vortex ring state; H-8, Ground control hazard; H-9, Collision avoidance malfunction; and H-12 Visual camera malfunction is regarded as catastrophic, which means that they might cause losses of life due to the extreme wind conditions for the drone operators, or loss of life for either drone operators or trespassers due to the drone accident due to malfunction. (ii) The associated economic consequence for the hazards, $\mathrm{H}-4$, H-8, H-9 and H-12 can go up to USD100,000 in some cases. (iii) The environmental impact of the hazard H-4 and H-13, bird attack, is characterised as significant. For instance, due to the collision of the drone with the bridge parts because of strong wind, that might lead to a massive amount of debris (of both drone and bridge parts) in the water below which can lead to aquaculture hazards. Due to the collision of the drone with the bridge parts there might be a fire that can lead to emissions harmful for the atmosphere, and also in case of the drone crashing in the forest, there is the possibility of fires that can lead to disastrous wildfires. 


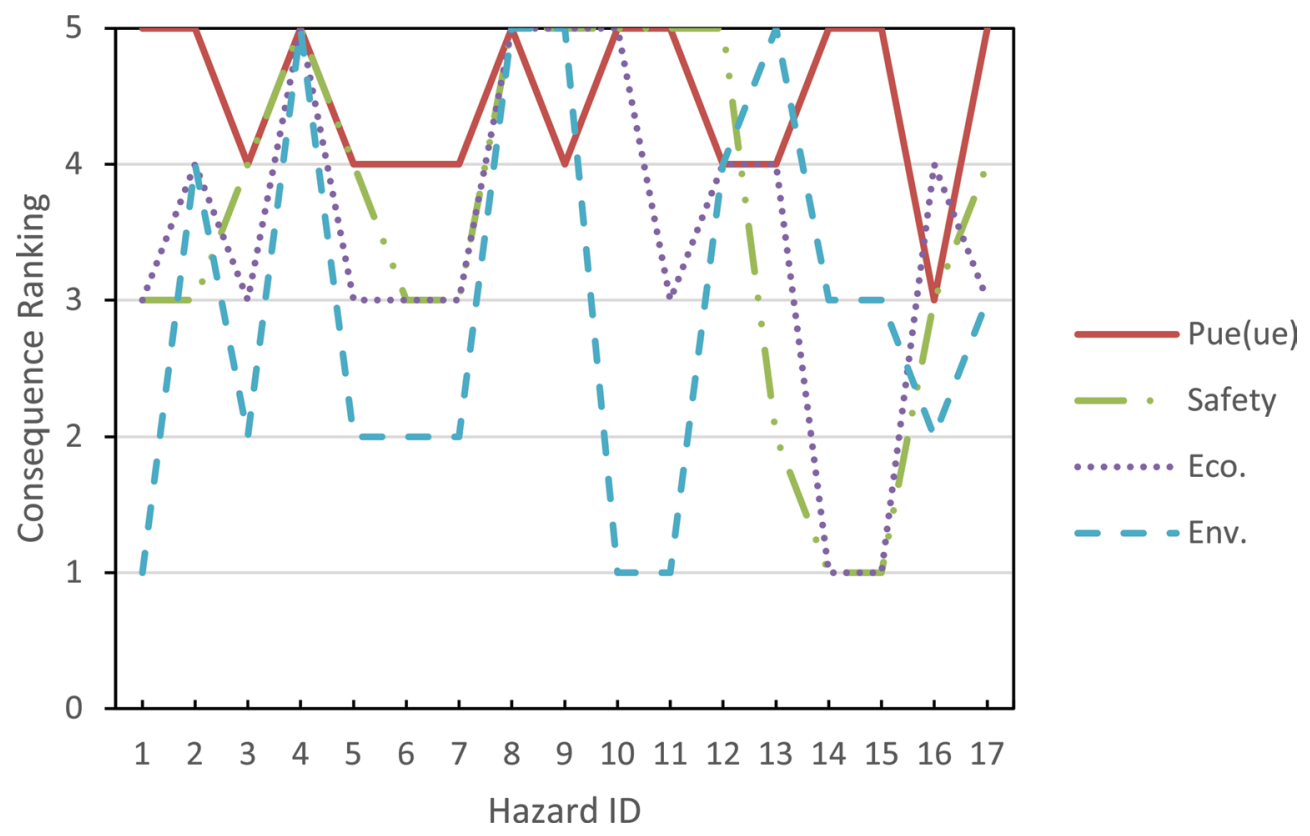

Figure 4: Risk profile for the drone-enabled bridge inspection in cold operating environment

Further, collision accidents with the birds can cause death for the birds, which is considered as a negative impact to the ecosystem. Therefore, to avoid the negative outcomes while carrying out the drone-enabled bridge inspection, one has to setup various types of safeguards, see Table 2.

\section{CONCLUDING REMARKS}

Drone deployment in bridge inspection could potentially save time and money. However, it also has various shortcomings. We have conducted a preliminary hazard analysis (PHA) for understanding the hazards existing in the use of drones for bridge inspections, in particular for cold operating environment and for future inspection planning. The findings are as follows: (i) we demonstrated a practical PHA and risk assessment for drone-enabled bridge inspection. The PHA concentrates on the technical related hazards and the environmental related hazards, which are due to the effects of cold and harsh environments on the reliability of human performance, i.e., the drone-pilot performance, recognizing that human actions are influenced by the cold environment. (ii) From the case study, we found that drone-enabled bridge inspections can be significantly affected by a number of hazards related to cold operating environment. Hazards such as wind, vortex ring state, ground control, collision avoidance malfunction; and visual camera malfunction can lead to catastrophic safety consequences, in extreme situation including losses of life. In addition, hazards including collision avoidance malfunction, drone total malfunction, disruption of passing ships/boats from under the bridge and vortex ring state can cause significant economic impacts, in some cases up to USD100,000 financial losses. Further, hazards such as collision accidents with the birds can leads to bird's casualty, which is regarded as a negative impact to the ecosystem.

Our intent is not to provide generalized advice on whether drone-enabled bridge inspection should replace the conventional inspection or not, since these prescriptions will be particular 
to and heterogeneous to types of bridges and accompanied drone rules and regulations. Rather, the intent is to highlight the fact that even if drone-enabled bridge inspection has a huge potential in the years to come, the associated hazard has to be investigated thoroughly. This will assist the decision maker to identify the most cost-effective and efficient bridge inspection procedures with minimum level of HSE-C (health, safety, and environment, and cost) risk.

\section{REFERENCES}

[1] E. Haugen., "Skjeggestadbrua: Om skredet, brukollapsen og pågående arbeider." http:// ngf.no/wp-content/uploads/2015/05/Skjeggestadbrua-Yngres-dag-2015-Eigil-HaugenSVV.pdf (accessed.

[2] S. Chen, D. F. Laefer, E. Mangina, S. I. Zolanvari, and J. Byrne, "UAV bridge inspection through evaluated 3D reconstructions," Journal of Bridge Engineering, vol. 24, no. 4, p. 05019001, 2019.

[3] J. Seo, J. P. Wacker, and L. Duque, "Evaluating the use of drones for timber bridge inspection," Gen. Tech. Rep. FPL-GTR-258. Madison, WI: US Department of Agriculture, Forest Service, Forest Products Laboratory. 1-152., vol. 258, pp. 1-152, 2018.

[4] J. Seo, L. Duque, and J. Wacker, "Drone-enabled bridge inspection methodology and application," Automation in Construction, vol. 94, pp. 112-126, 2018.

[5] A. Zulifqar, M. Cabieses, A. Mikhail, and N. Khan, "Design of a bridge inspection system (BIS) to reduce time and cost," George Mason University: Farifax, VA, USA, 2014.

[6] J. Wells and B. Lovelace, "Improving the Quality of Bridge Inspections Using Unmanned Aircraft Systems (UAS)," 2018.

[7] Y. Z. Ayele and E. L. Droguett, "Application of UAVs for Bridge Inspection and Resilience Assessment," in 29th European Safety and Reliability Conference, Hannover, Germany, M. Beer and E. Zio, Eds., 2019, doi: 10.3850/978-981-11-2724-3_0954-cd.

[8] Y. Z. Ayele, "Drones for inspecting aging bridges.," presented at the International Conference on Natural Hazards and Infrastructure. ISSN 2623-4513., Chania, Crete Island, Greece, 23-26 June, 2019, 2019.

[9] H.-J. Jung, J.-H. Lee, and I.-H. Kim, "Challenging issues and solutions of bridge inspection technology using unmanned aerial vehicles," in Sensors and Smart Structures Technologies for Civil, Mechanical, and Aerospace Systems 2018, 2018, vol. 10598: International Society for Optics and Photonics, p. 1059802.

[10] V. L. Foreman, F. M. Favaró, J. H. Saleh, and C. W. Johnson, Software in military aviation and drone mishaps: analysis and recommendations for the investigation process, Reliability Engineering \& System Safety, vol. 137, pp. 101-111, 2015.

[11] T. Rakha and A. Gorodetsky, Review of Unmanned Aerial System (UAS) applications in the built environment: towards automated building inspection procedures using drones, Automation in Construction, vol. 93, pp. 252-264, 2018.

[12] E. Ciampa, L. De Vito, and M. R. Pecce, "Practical issues on the use of drones for construction inspections," in Journal of Physics: Conference Series, 2019, vol. 1249, no. 1: IOP Publishing, p. 012016.

[13] Y. Z. Ayele and B. Ashrafi, "PRELIMINARY HAZARD ANALYSIS FOR UAVASSISTED BRIDGE INSPECTION," presented at the WIT Transactions on the Built Environment., 2020. 
[14] M. Rausand, "Preliminary hazard analysis," Norwegian University of Science and Technology, 2005.

[15] C. M. Belcastro, R. L. Newman, J. Evans, D. H. Klyde, L. C. Barr, and E. Ancel, "Hazards identification and analysis for unmanned aircraft system operations," in 17th AIAA Aviation Technology, Integration, and Operations Conference, 2017, p. 3269.

[16] US Occupational Safety \& Health Administration. "Infrastructure Repair and Restoration: Roadway and Bridge Inspection and Repair." https://www.osha.gov/ SLTC/etools/hurricane/roadway-bridge.html (accessed 12.03.2019, 2019).

[17] R. Dobbs, H. Pohl, and D. Lin, Infrastructure Productivity: How to Save \$1 Trillion a Year. McKinsey Global Institute. ed: Print, 2013.

[18] Y. Z. Ayele, A. Barabadi, and T. Markeset, "Spare part transportation management in High North," 2013.

[19] C. Okoh, R. Roy, J. Mehnen, and L. Redding, "Overview of remaining useful life prediction techniques in through-life engineering services," Procedia CIRP, vol. 16, pp. 158-163, 2014.

[20] C. von der Haar, S. Marx, and M. Hansen, Monitoring of bridges - detection of traffic loads, in Proc. of the 6th Int. Conf. on Bridge Maintenance, Safety and Management (IABMAS 2012), Stresa, Lago Maggiore, Italien, 2012, pp. 3942-3947.

[21] Bridge Masters. "Drone Inspections for At-Risk Bridges: A New Frontier " https:// bridgemastersinc.com/drone-inspections-at-risk-bridges/ (accessed.

[22] N. Ortiz, T. Wheeler, R. Breeding, S. Hora, M. Meyer, and R. Keeney, "Use of expert judgment in NUREG-1150," Nuclear engineering and design, vol. 126, no. 3, pp. 313331, 1991.

[23] S. C. Hora, "Expert Judgement in Risk Analysis," 2009.

[24] S. E. Chang, T. McDaniels, J. Fox, R. Dhariwal, and H. Longstaff, “Toward DisasterResilient Cities: Characterizing Resilience of Infrastructure Systems with Expert Judgments," Risk analysis, vol. 34, no. 3, pp. 416-434, 2014.

[25] R. M. Cooke, "Experts in uncertainty: opinion and subjective probability in science," 1991. 


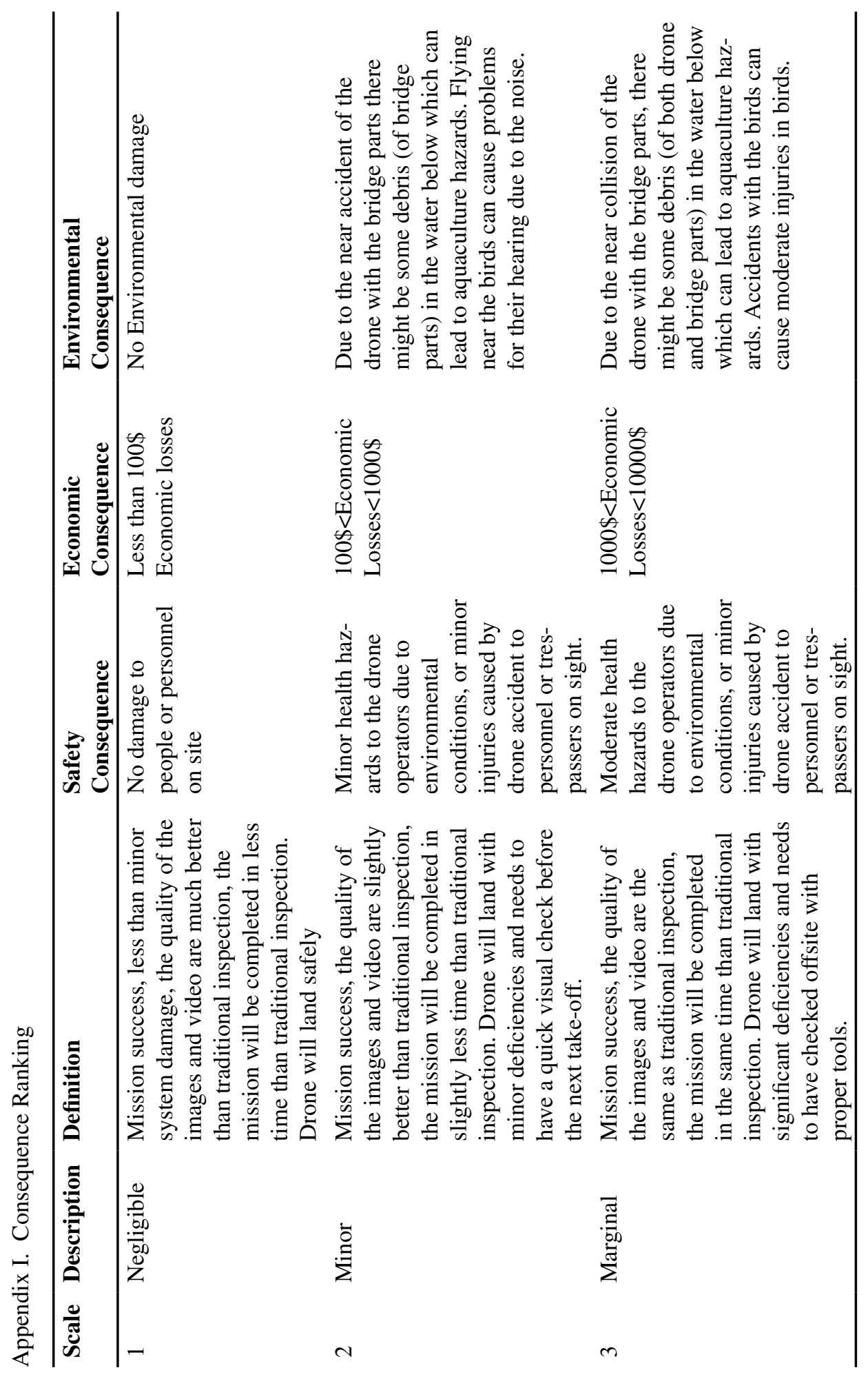




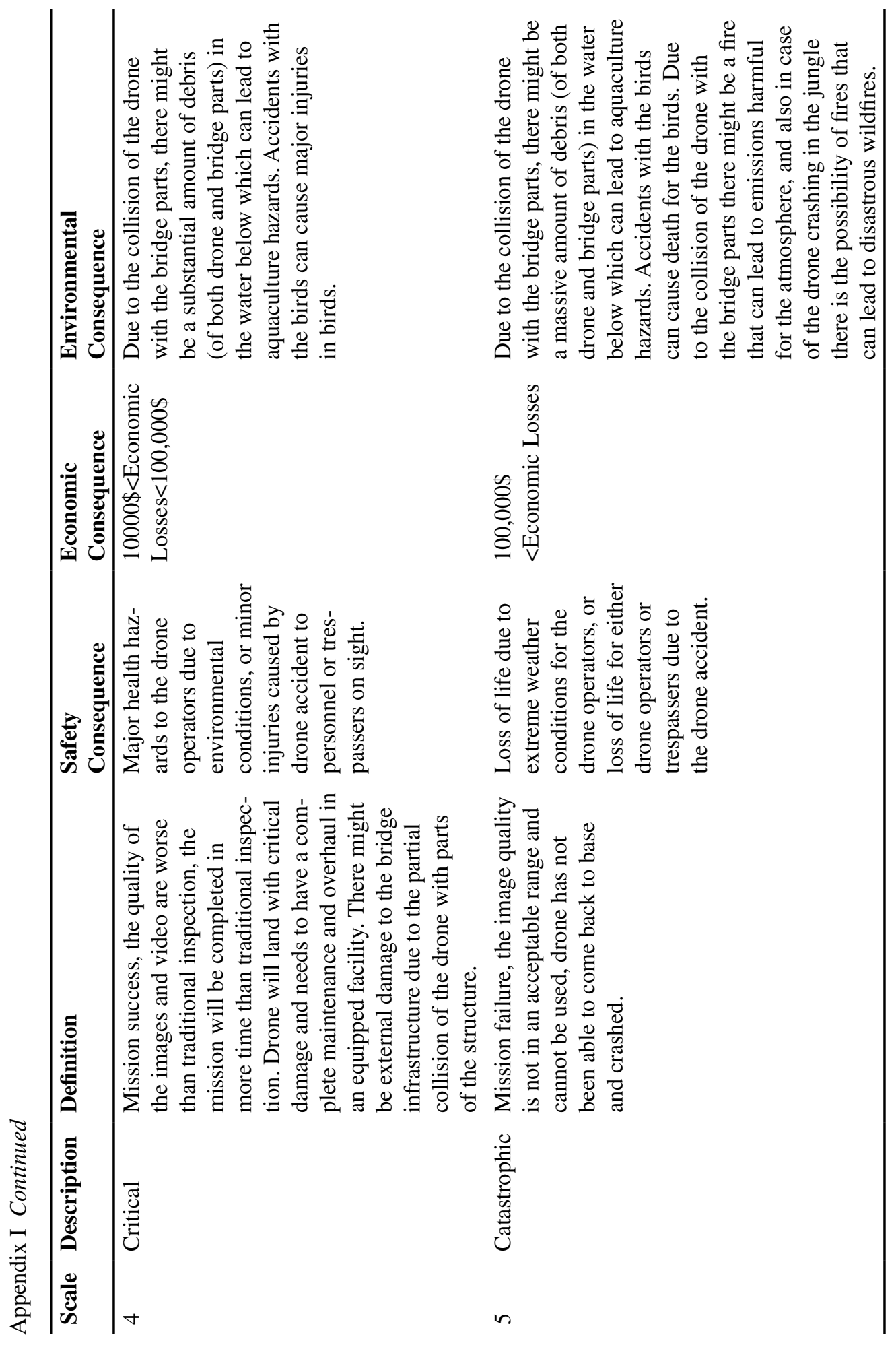


Appendix II. Probability Ranking

\begin{tabular}{lll}
\hline Probability & Description & Definition \\
\hline 1 & Very unlikely, rare probability & $\begin{array}{l}\text { Negligible, insignificant } \\
\text { consequences }\end{array}$ \\
2 & Unlikely, possible but not likely & $\begin{array}{l}\text { Slight, minor consequences } \\
\text { Moderate }\end{array}$ \\
3 & $\begin{array}{l}\text { Possible, can occur once in 1000 } \\
\text { flights }\end{array}$ & $\begin{array}{l}\text { Major, cause high or significant } \\
\text { Likely, anticipated few times in } \\
4\end{array}$ \\
$\begin{array}{l}1000 \text { flights } \\
\text { Very likely, almost certain }\end{array}$ & $\begin{array}{l}\text { Catastrophic, very high or severe } \\
\text { damage }\end{array}$ \\
\hline
\end{tabular}

